Ética e política 


\section{De Vargas a Itamar: políticas e programas de alimentação e nutrição}

ALBERTO CARVALHO DA SILVA

$\mathrm{N}$

o BRAsIL, a subnutrição começou a ser identificada como problema social e de saúde pública durante o governo Vargas, a partir da segunda metade da década de 30. Reconheceu-se a associação com pobreza extrema e com práticas alimentares e serviços de saúde inadequados e que somente a correção destes determinantes poderia levar a uma solução definitiva. Mas não escapou a Vargas e a seus sucessores que esta correção era um processo de longo prazo e que, durante este, seriam necessárias medidas compensatórias dirigidas aos grupos de maior risco.

Durante os anos que se seguiram esta situação pouco se modificou apesar do considerável crescimento da economia e das medidas compensatórias adotadas, sempre conduzidas com irregularidade e ineficiência, e que podem ser agrupadas em três fases: primeiras iniciativas (a partir de 1940); período do Pronan (1972 a 1989) e período atual (a partir de 1990).

\section{Primeiras iniciativas (a partir de 1940)}

Na segunda metade da década de 30, o Governo Vargas, como parte de sua política trabalhista, tomou duas medidas que deveriam ter influência na alimentação da classe trabalhadora: o salário mínimo (1), que deveria "satisfazer às necessidades normais do trabalhador e sua família"; e o Serviço de Alimentação da Previdência Social (Saps), criado em 1940, com os encargos de promover a instalação de refeitórios em empresas maiores, fornecer refeições nas menores, vender alimentos a preço de custo a trabalhadores com família numerosa, proporcionar educação alimentar, formar pessoal técnico especializado e apoiar pesquisas sobre alimentos e situação alimentar da população.

O Saps expandiu-se mais no Rio de Janeiro onde, em 1945, mantinha seis restaurantes populares e fiscalizava 42 , distribuía refeições quentes em caminhōes térmicos a mais de $\mathbf{5 0}$ firmas e oferecia um programa de desjejum escolar com refeiçốes à base de leite, frutas e pão, somando 450 cal. 
Em 1942, foi criada a Coordenação da Mobilização Econômica - CME, que incluía um Serviço Técnico de Alimentação Nacional, com o objetivo de orientar a produção agrícola $\mathrm{e}$ industrial de alimentos e racionalizar a produção agropecuária e a comercialização, além de prestar assistência técnica à indústria através de um laboratório de tecnologia de alimentos.

Em 1945, foi instalada a Comissão Nacional de Alimentação (CNA), com funçóes de definir a política nacional de alimentaçăo, estudar o estado de nutriçāo e os hábitos alimentares da população, acompanhar e estimular as pesquisas relativas às questôes e problemas de alimentação, trabalhar pela correção de defeitos e deficiências da dieta brasileira estimulando e acompanhando campanhas educativas, $\mathrm{e}$ contribuir para o desenvolvimento da indústria de alimentos desidratados.

Em janeiro de 1946 fundou-se o Instituto Nacional de Nutrição (INN) (2), que incorporou o Instituto de Tecnologia Alimentar criado em 1944. A nova entidade era dividida em quatro seçóes: pesquisa biológica, pesquisa social, educação alimentar e patologia clínica.

Em 1952, foi elaborado o plano Conjuntura Alimentar e Problemas de Nutrição no Brasil abrangendo inquéritos nutricionais, expansão da merenda escolar, assistência alimentar a adolescentes, programas regionais, enriquecimento de alimentos básicos, apoio à indústria de alimentos. Deste projeto ambicioso sobreviveu apenas a campanha da merenda escolar, sob o controle do Ministério da Educação a partir de 1955. Com o apoio do Fundo Internacional do Socorro à Infầncia, a campanha expandiu-se rapidamente a ponto de, em 1968, os dados oficiais registrarem uma cobertura de 9,5 milhões de crianças correspondente a $75 \%$ das matrículas no ensino fundamental, com a distribuição anual de mais de 50.000 toneladas de alimentos. Destes, quase $50 \%$ eram doados através de World Food Program e Food for Development.

A quantidade de alimento recebida entre 1950 e 1970, como doação ou a preços simbólicos, é difícil de precisar. No biênio 1968-1969, Food for Development contribuiu com 187.000 toneladas, em boa parte distribuídas através de programas de atenção materno-infantil, assistência ao trabalhador e organizaçóes religiosas. Simultaneamente, com apoio da Usaid (United States Agency for International Development) foram feitas tentativas para introduzir ou desenvolver localmente alimentos formulados de baixo custo tais como Soleina, Vitasoy, Sacy, Fortifex, Cerelina, concentrados protéicos de peixe e macarráo com soja. Programas visando a educação nutricional e a produção de alimentos a domicílio e nas escolas foram implantados na Paraíba e depois em outros estados do Nordeste, do Centro e do Sul.

Com exceção da merenda escolar, nenhum destes esforços prosperou mas acumularam-se durante o período informaçóes que não deixaram dúvida quanto 
à gravidade da situação. Os numerosos inquéritos conduzidos pela CNA em diversas regióes do país; os estudos de Waterlow \& Vergara (1955) e Parahym (1958); o inquérito do Interdepartmental Committee on Nutrition for National Development em cinco estados do Nordeste (1963); os trabalhos do grupo de Nelson Chaves, na Zona da Mata (1965-1966); e o Estudo do Consumo Alimentar, pela Fundação Getúlio Vargas (1961-1963), todos apontavam para altos índices de desnutrição rural e urbana, com déficit calórico e protéico acompanhado de anemia e, ao menos em algumas regióes do Nordeste, hipovitaminose A. Paralelamente, um amplo estudo do Ministério da Saúde, em 1955, identificava o bócio endêmico como grave problema de saúde pública.

É surpreendente que, apesar dos conhecimentos acumulados, da oferta de excedentes alimentares de outros países e das estruturas burocráticas que emergiram ao longo desses anos, nenhum outro programa de alimentação e nutrição, além da $\mathrm{Me}$ renda Escolar, tenha sobrevivido. E também que, apesar de, já nessa época, terem sido criados institutos de nutrição nas universidades federais de Pernambuco e do Rio de Janeiro, a capacidade de pesquisa e treinamento àvançado em nutrição humana não tenha alcançado o nível que seria de se desejar, face à gravidade do problema social.

\section{Pronan e Inan (1972-1989)}

Um fato novo ocorreu em 1972 , quando o Presidente da República aprovou a criação do Instituto Nacional de Alimentaçáo e Nutrição (Inan) $(3,4)$ autarquia vinculada ao Ministério da Saúde com os encargos de: assistir o governo na formula-

\section{Glossário}

CME - Coordenação da Mobilizaçáo Económica

CNA - Comissão Nacional de Alimentação

Cobal - Companhia Brasileira de Alimentaçáo

Conab - Companhia Nacional de Abastecimento

Consea - Conselho de Segurança Alimentar

Emater - Empresa Brasileira de Assistência Técnica e Expansão Rural

FAE - Fundaçăo de Assisténcia ao Educando

GG - Gente da Gente [Gente como a Gente]

Thac - Iniciativa Hospital Amigo da Criança

Inan - Instituto Nacional de Alimentação e Nutrição

INN - Instituto Nacional de Nutrição

Paie - Programa de Alimentaçäo dos Irmáos dos Escolares

Paismc - Programa de Açóes Integradas da Saúde da Mulher e da Criança

PAN - Programa de Apoio Nutricional

PAP - Programa de Alimentaçăo Popular

PAT - Programa de Alimentaçăo ao Trabalhador

PCA - Programa de Complementação Alimentar

Pcbe - Programa de Combate ao Bócio Endémico

Pccne - Programa de Combate as Carências Nutricionais Especificas 
ção da política nacional de alimentação e nutrição; propor o Programa Nacional de Alimentação e Nutrição (Pronan), promover e fiscalizar a sua execução e avaliar os resultados; e estimular pesquisa científica de apoio.

O Pronan definiu como alvo as gestantes, nutrizes e crianças até sete anos na população de baixa renda e os escolares de sete a 14 anos.

O primeiro Pronan (1973-1974) teve sua execução prejudicada por dificuldades administrativas. O Pronan II (1976-1979) ofereceu o primeiro modelo de uma política nacional incluindo suplementação alimentar, amparo ao pequeno produtor rural, combate às carências específicas, alimentação do trabalhador e apoio à realização de pesquisas e capacitação de recursos humanos (5).

Além da merenda, que passou a denominar-se Programa Nacional de Alimentação Escolar, nos anos seguintes foram implantados, sob a égide do Pronan, 10 programas e ações de alimentação e nutrição e, em 1975, foi assinado um convênio Inan-Banco Mundial em apoio ao Programa de Nutriçāo Brasil, que se destinava a testar formas e canais de intervenção, desenvolver capacidades técnica e gerencial e promover pesquisa e treinamento.

Dos programas que integraram o Pronan, seis ficaram sob o comando do Inan: Nutrição em Saúde, Abastecimento de Alimentos em Áreas de Baixa Renda, Racionalização da Produção de Alimentos Básicos, Incentivo ao Aleitamento Materno, Combate às Carências Nutricionais Especificas e Sistema de Vigilância Alimentar e Nutricional. Ficaram a cargo de outros Ministérios, escapando ao controle do Inan, os programas de Complementação Alimentar, Alimentação do Trabalhador, Alimentação Escolar e dos Irmãos do Escolar, Leite para Crianças Carentes e Programa de Alimentação Popular.

\section{Programa Nutrição Brasil (PNB)}

O convênio com o Banco Mundial (6), visando a criar condiçóes para que em quatro anos o Brasil se tornasse apto a planejar e conduzir uma política eficaz de combate à desnutrição, tinha quatro componentes: testar e comparar redes de prestação de serviços como canais para programas de alimentação e nutrição; desenvolver alimentos de baixo custo e alto valor nutricional; desenvolver a capacidade de planejamento, gestão, acompanhamento e avaliaçáo em políticas de alimentação e nutrição; e formar um quadro interdisciplinar de técnicos e pesquisadores em políticas de alimentos e nutrição.

Desses quatro itens, apenas o primeiro teve um desenvolvimento próximo do previsto. Foram testadas três redes de serviços: a extensão rural, através da Emater (Empresa Brasileira de Assistência Técnica e Extensão Rural), combinan- 
do extensão agrícola, saúde e nutrição para pequenos produtores, em área rural de Sergipe (Pramense); a rede escolar, combinando estimulação social e suplementação alimentar do pré-escolar com educação materna, em Recife (Proape); e, também em Recife, associaçáo do supermercado da Cobal (Companhia Brasileira de Alimentação) (7) com a rede de saúde, para testar o impacto de subsídios de preços de alimentos básicos na nutrição do pré-escolar (Pins).

É duvidoso que o PNB tenha exercido uma influência positiva. Dos três projetos sobre redes de serviços, o Proape teve alguma sobrevida, mas os outros dois foram completamente extintos. Ao contrário do que se esperava, a avaliação de cada um desses três programas não contribuiu para a incorporação de um sistema de acompanhamento e avaliação no Pronan. Os planos de promover o desenvolvimento de alimentos formulados e enriquecidos para uso em programas de suplementação tiveram pouco apoio do Inan. $E$ a promoção de pesquisa $e$ treinamento ficou muito aquém das expectativas.

\section{Os componentes do Pronan: programas sob o comando do Inan - Ministério da Saúde e Programa de Nutrição em Saúde (PNS)}

O Programa de Nutrição em Saúde, iniciado em 1975, propunha-se a distribuir alimentos básicos - arroz, açúcar, feijāo fubá, farinha de mandioca e leite em pó - a gestantes, nutrizes e crianças de seis meses a sete anos, em famílias de baixa renda (8), com prioridade para as regióes mais pobres e suprindo $45 \%$ das necessidades diárias. Os alimentos, adquiridos pela Cobal com re-
Pins - Projeto Integrado de Nutrição

Pnae - Programa Nacional de Alimentação Escolar

PNB - Programa de Nutrição Brasil

PNS - Programa de Nutrição em Saúde

Pniam - Programa Nacional de Incentivo ao Aleitamento Materno

Pnlcc - Programa Nacional do Leite para as Crianças Carentes

Pramense - Projeto Experimental de Produção de Alimentos e Melhoria do Estado Nutricional em Áreas de Baixa Renda em Sergipe

Proab - Programa de Alimentos Básicos em Áreas de Baixa Renda

Proape - Programa Alimentar do Pré-Escolar

Procab - Programa de Racionalização da Produção de Alimentos Básicos

Prodea - Programa de Distribuição Emergencial de Alimentos

Pronan - Programa Nacional de Alimentação e Nutrição

PSA - Programa de Suplementação Alimentar

PSN - Pesquisa Nacional em Saúde e Nutriçăo

Sapes - Serviço de Alimentação da Previdência Social

Sisvan - Sistema de Vigilância Alimentar e Nutricional

Unicef - United Nations Children Fund

Usaid - United States Agency for International Development 
cursos do Inan, eram distribuídos pelas secretarias de saúde dos estados, através de suas redes de serviços.

A partir de 1985, o PNS passou a ser denominado Programa de Suplementação Alimentar (PSA), tendo como grupo alvo gestantes, nutrizes e crianças até quatro anos (9). Pretendia-se que, já em 1986, a cobertura fosse de 12 milhóes de beneficiários, abrangesse todo país com uma distribuição de 720.000 toneladas de alimentos e maior integração com ações em saúde, com redução de $40 \%$ na mortalidade infantil até 1990 (10).

Os dados originais sobre população atendida e alimentos distribuídos até 1989 são apresentados no quadro 1 .

\section{Quadro 1}

População atendida e alimento distribuído nos programas de suplementação alimentar

\begin{tabular}{lcccrrrrr}
\hline & \multicolumn{3}{c}{ População atendida (x1000) } & & \multicolumn{3}{c}{ Quantidade de alimento (ton.) } \\
\cline { 2 - 3 } \cline { 6 - 7 } Ano & PSA & PNAE & PCA & & PSA & PNAE & PCA \\
\hline 1975 & 452 & 11.138 & - & & 5.042 & 66.821 & - \\
1976 & 1.021 & 11.769 & - & & 33.982 & 128.648 & - \\
1977 & 1.005 & 12.970 & 242 & & 74.260 & 132.957 & 7.014 \\
1978 & 2.922 & 14.072 & 286 & & 98.547 & 136.591 & 7.099 \\
1979 & 2.413 & 14.004 & 292 & & 97.634 & 112.813 & 9.216 \\
1980 & 2.469 & 15.051 & 290 & & 110.320 & 103.495 & 9.000 \\
1981 & 2.510 & 15.623 & 350 & & 93.220 & 125.852 & 9.023 \\
1982 & 3.393 & 18.720 & 389 & & 95.087 & 127.974 & 10.683 \\
1983 & 4.192 & 19.542 & 700 & & 150.411 & 96.717 & 12.990 \\
1984 & 4.387 & 20.838 & 750 & & 123.616 & 119.375 & 13.203 \\
1985 & 3.697 & 21.733 & 997 & & 61.172 & 240.890 & 17.536 \\
1986 & 8.682 & $31.801^{(2)}$ & 1.060 & & 250.930 & 288.701 & 13.507 \\
1987 & 9.300 & 30.026 & 1.178 & & 212.000 & 155.613 & 12.914 \\
1988 & 9.300 & 32.000 & 1.975 & & 65.200 & 190.346 & 45.525 \\
1989 (1) & $6.200(1)$ & 32.000 & 1.852 & & 60.200 & 100.843 & 35.000 \\
\hline
\end{tabular}

(1) A partir de 1989, a faixa etária das crianças reduz-se para menores de 36 meses;

(2) A partir de 1986, inclui o Paie.

\section{Programa de Alimentos Básicos em Áreas de Baixa Renda (Proab)}

O Proab propunha-se a abastecer os pequenos varejistas, em áreas pobres, com alimentos básicos a preços reduzidos, com a condição de que as margens de lucro na comercialização não ultrapassassem 20\% (11). Iniciado em $1979 \mathrm{em}$ dois bairros de Recife, o programa teria alcançado em 1987 uma cobertura de 
3,4 milhões em nove capitais do Nordeste, comercializando 121.725 toneladas de alimentos através de 4.246 varejistas (quadro 2). A partir de 1985, foi implantado em outras regióes o Programa de Alimentação Popular (PAP), sendo mantido o Proab nas capitais do Nordeste.

\section{Programa de Racionalização}

\section{da Produção de Alimentos Básicos (Procab)}

Através da Cobal, com recursos do Inan administrados pelo Banco Nacional de Crédito Cooperativo, eram comprados alimentos básicos diretamente de pequenos produtores e canalizados para os programas do Pronan. O programa foi implantada em 1977 na Paraíba e expandido a sete estados do Nordeste. Seu principal objetivo era assegurar a comercialização da produção a preços mínimos aos pequenos agricultores, mas a oferta foi limitada em virtude dos baixos índices de produção agravados pela seca. Em 1985, apesar de contar com cerca de 600.000 produtores cadastrados no Nordeste e Norte, o Procab pode comprar apenas 2.200 toneladas de alimentos (12).

\section{Programa Nacional de Incentivo ao Aleitamento Materno (Pniam)}

Iniciado em 1981 com apoio da Unicef e precedido de um amplo estudo de referência em São Paulo e'Recife, o Pniam propunha-se a estimular o aleitamento materno mediante promoção de sua valorização social, difusão de conhecimentos sobre práticas de amamentação e orientação às instituições prestadoras de serviços de saúde na assistência à nutriz. Após considerável repercussão inicial, o Pniam perdeu impulso com sua subordinação ao Programa de Ações Integradas da Saúde da Mulher e da Criança (Paismc) (13) em 1983. A partir de 1985, o programa diminuiu progressivamente de intensidade.

\section{Programa de Combate}

às Carências Nutricionais Específicas (Pccne)

Sob esta rubrica incluiu-se a prevenção e tratamento do bócio endêmico, hipovitaminose A, anemia ferropriva e cárie dental. O Programa de Combate ao Bócio Endêmico (Pcbe) foi iniciado em 1975, no Rio Grande do Norte, com fornecimento de iodato à indústria salineira. A partir de 1983, o programa foi expandido a 172 indústrias em 15 estados. Cabia ao Inan importar o iodato, distribuí-lo às empresas e controlar os níveis de iodaçáo do sal no comércio. Em 1975 , foram iodadas 1,7 milhões de toneladas de sal, comprovando-se níveis adequados de iodo em $97,4 \%$ das amostras recolhidas. A um custo anual de dois centavos de dólar per capita, o bócio endêmico estava praticamente sob controle em 1990. 
No combate à hipovitaminose A não se chegou a decisão quanto à tecnologia a ser adotada. Em 1983, 248.000 pessoas receberam vitamina A oral nas regiốes de risco, nos estados de Pernambuco, Paraíba e Minas Gerais. Em 1984, foi incluído o estado de Goiás e o número de pessoas chegou a 742.000; em 1986, um milhão de crianças nos estados do Rio Grande do Norte, Piauí, Pernambuco, Alagoas e Sergipe receberam vitamina A com a vacina contra a poliomielite.

No combate à anemia ferropriva, em 1973, cerca de 400.000 pessoas receberam cápsulas de sulfato ferroso e vermífugo nos estados de Paraíba, Pernambuco, Minas Gerais e Goiás, mas, já em 1984, esse número baixou para 275.000 (14).

\section{Sistema de Vigilância}

\section{Alimentar e Nutricional (Sisvan)}

Embora considerado como componente fundamental de uma política de nutrição em áreas endêmicas, os esforços para desenvolvimento e implantação do Sisvan só foram iniciados em 1983-1984. O Sistema, desenvolvido pela Fundação Joaquim Nabuco, baseava-se em um elenco de indicadores biológicos, sócioeconômicos e demográficos (15). O modelo foi testado em Récife e na Paraíba mas o programa não chegou a ser implantado.

\section{Programas de outros ministérios:}

Programa Nacional de Alimentação Escolar (Pnae)

e Programa de Alimentação dos Irmãos dos Escolares (Paie)

O Pnae, o mais antigo dos programas de nutrição do país (16) e um dos maiores em seu gênero, conduzido pela Fundação de Assistência ao Educando (FAE), do Ministério da Educação e Cultura, propóe-se a distribuir alimentos a crianças do curso fundamental - sete a 14 anos, nas escolas públicas e nas mantidas por organizaçóes filantrópicas, durante os 200 dias do ano letivo. Em 1986 foi acrescentado o Paie ou Programa Irmãozinhos, estendendo a distribuição aos irmãos de escolares entre quatro e seis anos de idade (17). O Pnae vem atendendo de $60 \%$ a $70 \%$ da população alvo, com distribuição anual média de $\mathbf{1 4 0 . 0 0 0}$ toneladas de alimentos, mas com considerável variação regional e anual, tanto na quantidade de alimento quanto no número de dias de merenda. $\mathrm{O}$ alimento distribuído representa de $7 \%$ a $20 \%$ das necessidades energéticas da criança, nos dias em que há distribuição. O Programa vem sendo descentralizado a partir de 1983, passando a sua gestão aos municípios. Em média, $40 \%$ dos alimentos distribuídos são formulados, o que encarece o programa mas facilita a distribuição e armazenagem. A meta do Paie em 1986 era distribuir 15\% da necessidade energética a sete milhões de irmãos dos escolares, mas esta previsão foi reduzida a 5,7 milhóes em 1989. A cobertura e a quantidade de alimento distribuído até 1989 por ambos os programas constam do quadro 1 . 


\section{Programa de Complementação Alimentar (PCA) (18)}

Iniciado em 1976, sob a égide da Legião Brasileira de Assıstência (LBA), o PCA distribuía, através de clubes, igrejas e outras organizações comunitárias, três alimentos formulados (19), suprindo $20 \%$ a $30 \%$ das necessidades individuais diárias em energia e proteínas. A partir de 1986 os formulados foram sendo substituídos por alimentos naturais, com melhor aceitação $(20)$ e foi incluído um componente de saúde (peso da criança e instruções à mãe sobre aleitamento, infecções, diarréia e uso de mistura salina). De uma distribuição de 7.000 toneladas de alimentos a 240.000 pessoas em 1977, o PCA atingiu 35.000 toneladas e 1.850.000 pessoas em 1989 (quadro 1).

\section{Programas de Alimentação do Trabalhador (PAT)}

O PAT foi iniciado pelo Ministério do Trabalho em 1977 e ofereceu refeições grandes $(1.400 \mathrm{cal})$ epequenas $(300 \mathrm{cal})$ a trabalhadores de baixa renda, a preços de até $20 \%$ do custo. Os outros $80 \%$ ficavam a cargo do setor público e do empregador (21). O programa expandiu-se rapidamente nos centros mais industrializados, passando a envolver o maior volume de recursos entre os componentes do Pronan, com dois terços das empresas participantes localizadas no estado de São Paulo. Um componente para volantes rurais foi interrompido em 1979. O PAT cresceu regularmente (quadro 2) alcançando 6,4 milhōes de trabalhadores em 1990 e 7,8 milhões em 1992 com, respectivamente, 34.000 e 39.181 empresas participantes (quadro 4).

Quadro 2

População atendida e alimentos comercializados nos programas intervindo na comercialização

\begin{tabular}{cccccccc}
\hline & \multicolumn{3}{c}{ População atendida $(\mathrm{x} 1000)$} & & \multicolumn{3}{c}{ Quantidade de alimento (ton.) } \\
\cline { 2 - 4 } \cline { 6 - 8 } Ano & PROAB & PAP & PAT & & PROAB & PAP & PAT(1) \\
\hline 1977 & - & - & 760 & & - & - & 66.412 \\
1978 & - & - & 1.070 & & - & - & 97.066 \\
1979 & 60 & - & 1.253 & & 1.575 & - & 118.920 \\
1980 & 100 & - & 1.702 & & 9.241 & - & - \\
1981 & 460 & - & 1.920 & & 16.882 & - & 168.480 \\
1982 & 460 & - & 2.161 & & 30.466 & - & - \\
1983 & 1.420 & - & 2.281 & & 67.354 & - & - \\
1984 & 2.122 & - & 2.023 & & 88.563 & - & 217.597 \\
1985 & 2.228 & 3.500 & 2.584 & & 71.785 & 16.495 & 162.545 \\
1986 & 2.794 & $10.000(2)$ & 2.897 & & 107.905 & $88.658(2)$ & - \\
1987 & 3.425 & 6.200 & 3.458 & & 121.725 & - & - \\
1988 & 3.433 & - & 4.410 & & 36.576 & - & - \\
1989 & - & - & 5.275 & & - & - & - \\
\hline
\end{tabular}

(1) Peso calculado a partir do número de refeiçóes e lanches e seu valor calórico;

(2) Valor estimado. 


\section{Programa Nacional do Leite para as Crianças Carentes (Pnlcc)}

Este programa, instituído em 1985 pela Presidência da República através da Secretaria Especial de Ação Comunitária, propôs-se a distribuir um litro de leite por dia e por criança menor de sete anos, a famílias com renda de até dois salários mínimos. O leite era adquirido no varejo através de cupons fabricados pela Casa da Moeda e distribuídos às famílias através de organizações comunitárias previamente credenciadas. O comércio descontava os cupons no Banco do Brasil para reembolso. Iniciado com um atendimento de 2,6 milhóes de crianças em 1986, o Pnlcc estendeu-se à área rural, alcançando 7,6 milhóes em 1989 e 7,8 milhōes em 1990, com a participação de cerca de 80.000 organizações comunitárias e a distribuição de 1,1 bilhões de litros de leite (quadro 3). O Pnlcc foi extinto em janeiro de 1990.

Quadro 3

Programa Nacional de Leite para Crianças Carentes (Pnlcc)

\begin{tabular}{cccc}
\hline Ano & $\begin{array}{c}\text { População atendida } \\
(\mathrm{x} 1000)\end{array}$ & $\begin{array}{c}\text { Leite distribuído } \\
\text { (milhares de litros) }\end{array}$ \\
\cline { 2 - 3 } 1986 & 2.652 & 144.099 \\
1987 & 6.020 & 635.854 \\
1988 & 7.560 & 1.055 .288 \\
1989 & 7.601 & 1.135 .804 \\
\hline
\end{tabular}

\section{Programa de Alimentação Popular (PAP)}

O PAP, implantado em 1985 pelo Ministério da Agricultura, propunha-se a vender alimentos a preços baixos à população urbana com renda familiar inferior a 2,5 salários mínimos, excluídas as nove capitais do Nordeste que continuavam atendidas pelo Proab. Os alimentos (22) eram adquiridos dos produtores pela Cobal (23), sem subsídios e vendidos diretamente a cooperativas de consumo. O PAP atingiu 6,2 milhões de pessoas em 1987 através de 3.700 varejistas em 23 cidades, mas declinou a partir de 1988, sendo interrompido em 1989.

\section{Relaçōes do Pronan com Cobal - Rede Somar}

Além de sua participação em componentes do Pronan, a Cobal mantinha uma rede de comercialização, a Rede Somar, abastecendo os pequenos varejistas com cerca de 600 itens a preços inferiores ou comparáveis aos praticados por supermercados e oferecia treinamento gerencial aos pequenos varejistas para que melho- 
rassem o planejamento de seus negócios. O número de lojistas associados aumentou de $885 \mathrm{em}$ 1978-1979 para $6.903 \mathrm{em} \mathrm{1987.} \mathrm{Todavia,} \mathrm{as} \mathrm{dificuldades} \mathrm{enfrenta-}$ das pela Cobal, inclusive quanto à transparência de suas operaçôes comerciais, impediram que a Rede Somar cumprisse o programa a que se propunha.

\section{Período atual (a partir de 1990)}

Ao assumir em 1990, o novo governo tinha à sua disposição a experiência de 15 anos em programas diversificados de alimentação e nutrição e um diagnóstico atualizado da situação nutricional do país (24). Todavia, em vez de usar esta base para aprimorar a política de nutrição e expurgá-la das falhas anteriores, procedeu o novo governo à dissolução ou simples abandono de quase todos os programas, mantendo apenas o Programa Nacional de Alimentação Escolar (Pnae) e o Programa de Alimentação do Trabalhador (PAT), com poucas alterações. PSA, PCA, Pniam e Pcbe não foram formalmente extintos, mas sofreram consideráveis modificaçóes e reduções nos recursos, a partir de 1991 (quadro 4).

Quadro 4

Componentes do Pronan mantidos no período 1990-1992

\begin{tabular}{|c|c|c|c|c|}
\hline Programa & Resultados & 1990 & 1991 & 1992 \\
\hline \multirow[t]{2}{*}{$\operatorname{PNAE}(1)$} & População atendida & 29.680 .968 & 29.065 .000 & 30.600 .000 \\
\hline & alimento distribuído(ton.) & 138.116 & 134.685 & 92.918 \\
\hline \multirow[t]{2}{*}{ PSA } & População atendida & 6.667 .000 & 6.667 .000 & 2.786 .000 \\
\hline & alimento distribuído(ton.) & 60.401 & 36.484 & $2.899(2)$ \\
\hline \multirow[t]{2}{*}{ PCA/PAN } & População atendida & 1.078 .000 & - & - \\
\hline & alimento distribuído(ton.) & $11.398(3)$ & - & 一 \\
\hline \multirow[t]{2}{*}{ PNLCC } & População atendida & 7.818 .000 & - & - \\
\hline & alimento distribuído(ton.) & 1.157 .316 & - & - \\
\hline \multirow[t]{2}{*}{ PAT } & População atendida & 6.431 .693 & 6.822 .917 & 7.847 .413 \\
\hline & empresas participantes & 33.999 & 37.751 & 42.213 \\
\hline PNIAM & \multicolumn{4}{|c|}{ atividade reduzida no período; coordenação da IHAC a partir de 1991.} \\
\hline \multicolumn{5}{|c|}{$\begin{array}{l}\text { Prev. Anemia Praticamente interrompidos. } \\
\text { e Hipov. A }\end{array}$} \\
\hline PCBE & \multicolumn{4}{|c|}{$\begin{array}{l}\text { Redução da aquisição do iodato de potássio; suspensão dos inquéritos } \\
\text { nas áreas sentinela. }\end{array}$} \\
\hline
\end{tabular}

(1) Inclui o PAIE que, em 1990, recebeu $\mathbf{1 7 . 8 \%}$ dos alimentos distribuidos;

(2) Leite em pó com recursos do extinto Pnlcc;

(3) Além de 1.6 milhões de cestas básicas adquiridas no último mês do ano.

O Pnae anunciou a meta de 30 milhóes de escolares 200 dias por ano e 460.000 toneladas de alimentos, mas limitou-se a adquirir ao redor de 130.000 toneladas/ano em 1990 e 1991 e $93.000 \mathrm{em}$ 1992, oferecendo 60 dias de merenda por ano em 1990 e 1991 e 32 dias em 1992 (25). O Paie, acoplado ao Pnae, cumpriu apenas $16 \%$ de suas metas $\mathrm{em} 1990$ e foi desativado em 1991. 
O PSA distribuiu apenas $17 \%$ da quantidade de alimento necessário em 1990 e $10 \%$ em 1991. Em 1992, a distribuição limitou-se a 2.899 toneladas de leite em pó do extinto Pnlcc.

O Pniam, além da insuficiência de recursos, ficou sem coordenação entre agosto de 1992 e junho de 1993. Atualmente o programa vem coordenando a Iniciativa Hospital Amigo da Criança, lançado pela Unicef, que representa um esforço internacional para incentivar $o$ aleitamento materno.

No Pcbe o governo adquiriu apenas $86,8 \%$ do iodato de potássio necessário em 1990 e 55,5\% em 1991. Na falta de dados epidemiológicos, não é possível avaliar se tal endemia, que estava praticamente erradicada no fim da década de 80 , continua sob controle.

Quanto ao PAT, com o desmonte da equipe responsável no Ministério do Trabalho, o registro de informaçóes ficou prejudicado a partir de 1990. A cobertura de oito milhões de trabalhadores em 1992 corresponde apenas a $44 \%$ dos que ganhavam até cinco salários mínimos, estando cadastrados apenas $7,8 \%$ das empresas que reuniam as condiçóes para participar do programa.

A inovação introduzida no final de 1990 foi o programa emergencial Gente da Gente, utilizando estoques públicos de alimentos para distribuição de uma cesta mensal de $16 \mathrm{~kg}$ a 655.000 famílias nordestinas atingidas pela seca, cobrindo $20 \%$ das suas necessidades protéicas e calóricas. O programa desenvolveu-se em duas etapas: GG I (novembro 1990 a maio 1991, 579 municípios em nove estados); e GG II (fevereiro a junho de 1992, 739 municípios em 10 estados). O planejamento e a distribuição contaram com a participação de governos dos estados e municípios, Sudene, Exército, Conab, Banco do Brasil, Casa da Moeda etc. (26).

Em março de 1993, face às conclusóes de uma comissão integrada por membros do Governo e da sociedade civil, foi criado o Conselho de Segurança Alimentar (Consea), que elaborou o Plano de Combate à Fome e à Miséria, elegendo quatro prioridades: combate à desnutrição materno-infantil; descentralização do Programa Nacional de Alimentação Escolar; revisão do Programa de Alimentação do Trabalhador; e uso dos estoques públicos em programas emergenciais.

O combate à desnutrição materna e infantil coube ao Programa de Atendimento aos Desnutridos e às Gestantes - Leite é Saúde, tendo como usuários crianças desnutridas de seis a 24 meses, seus irmãos (até dois), de dois a quatro anos (contactos) e gestantes em risco nutricional. As crianças desnutridas devem receber, por dia, um litro de leite ou $120 \mathrm{~g}$ de leite em pó e $24 \mathrm{ml}$ de b́leo vegetal, suprindo $820 \mathrm{cal} \mathrm{e} 36 \mathrm{~g}$ de proteína. Os contactos e as gestantes recebem meio 
litro de leite. O programa é executado pelos municípios através de suas redes de saúde, com recursos repassados pelo Ministério da Saúde. Pretende-se chegar a 10 milhốes de beneficiários em 1995, a um custo anual equivalente a um bilhão de dólares (27).

A descentralização (municipalização) do Programa Nacional de Alimentação Escolar deve ser concluída até o fim de 1994 (28), mantendo-se a meta de distribuição de $15 \%$ das necessidades nutricionais a 30,6 milhões de crianças, 200 dias por ano, a um custo de US\$ 800 milhões (29).

Quanto ao Programa de Alimentação do Trabalhador, em 1993, seu aperfeiçoamento, ampliação e flexibilização foram objeto de um amplo debate com a sociedade civil, coordenado por uma comissão técnica no âmbito do Ministério do Trabalho. Pretende-se ampliar o atendimento que, atualmente, se limita à metade dos trabalhadores com até cinco salários mínimos, divulgar o programa junto a trabalhadores e empresas, melhorar a qualidade das refeiçõos e agilizar a administraçăo (30).

A utilização dos estoques públicos deu-se sob a forma da distribuição de feijão a famílias com renda familiar até dois salários mínimos e do Programa de Distribuição Emergencial de Alimentos (Prodea). A distribuição de feijão (31), no total 87.882 toneladas no valor estimado de US\$ 28 milhões, foi feita através das prefeituras, entre março e setembro de 1993. Colaboraram na sua organização e implementação o Ministério do Bem-Estar Social, o Banco do Brasil, a Conab e as prefeituras. O Prodea teve por objetivo distribuir 205.000 toneladas de alimentos (32) por mês, durante pelo menos quatro meses, em 1.162 municípios nordestinos em estado de calamidade pública devido à seca. A gestão do programa coube à Comissão Nacional Executiva, sob coordenação da Conab, com representantes dos Ministérios da Agricultura, Integração Regional, Fazenda e Exército, além do Banco do Brasil e de dois representantes indicados pelo Consea. Embora tenha havido boa aceitação dos alimentos in natura, a população mostrou preferência por alimentos processados e empacotados.

Decidiu-se retomar os programas de controle das carências específicas e Programa Nacional de Incentivo ao Alimento Materno (Pniam), agora associado ao programa Iniciativa Hospital Amigo da Criança.

Foi também decidido retomar o programa de Vigilância Alimentar e Nutricional. Inicialmente, a sua execução ficou a cargo dos municípios, sem critérios uniformes que permitissem estabelecer comparações. Mais recentemente foi criada uma comissão central com o objetivo de estruturar, dar uniformidade e criar condiçóes para acompanhamento e reajuste de medidas em andamento. 


\section{Investimento}

De 1978 a 1993 o Brasil investiu o equivalente a cerca de US\$ 8,2 bilhốes em programas de alimentação e nutrição. $O$ investimento cresceu lentamente até 1984, aumentou consideravelmente até 1990 e sofreu uma queda abrupta em 1991 e 1992, com alguma recuperação em 1993 (quadro 5). De pouco mais de $0,05 \%$ do PIB ou $2,8 \%$ do investimento em saúde em 1978, os programas de nutrição chegaram, respectivamente, a cerca de 0,3\% e 6\% em 1989-1990.

Ao longo de todo o período, os programas de suplementação alimentar deram conta de $95 \%$ ou mais dos dispêndios. Até 1986, dois deles - Programa de Nutrição em Saúde/Programa de Suplementação Alimentar e Programa Nacional de Alimentação Escolar - foram responsáveis por mais de 80\% e, de 1987 a 1990, teve grande participação o Programa Nacional de Leite para Crianças Carentes, somando, com os outros dois, de $88,5 \%$ a $92,6 \%$. Componentes de impacto nutricional comprovado e baixo custo como Pniam, Combate a Carências Específicas e Sistema de Vigilância Alimentar e Nutricional tiveram apoio decrescente a partir de 1987.

\section{Comentários e conclusões}

A avaliação da eficiência com que o Pronan se desenvolveu no período em que esteve em plena atividade (1975-1989), tanto em conjunto quanto em cada um dos componentes, é, atualmente, inviável. Para a maioria dos programas dispóe-se apenas dos dados oficiais sobre cobertura, quantidades de alimentos, distribuição regional e custos, e não de dados sobre o desempenho real. Atrasos na liberação de recursos sem correção monetária em períodos de inflação acentuada dificultam os cálculos do investimento real.

A descentralização dos programas, condição para uma gestão eficiente e ajustada às necessidades, condiçóes e recursos de cada região e para estimular a participação das entidades públicas e particulares locais, restringe-se praticamente ao PNS e ao Pnae e neste, apenas a partir de 1983.

Duplicaçóes da população-alvo em diferentes programas e falta de articulação entre eles tornam difícil a análise dos resultados atribuídos a cada componente, pouco adiantando as recomendaçóes das diveras comissóes que analisaram este problema (33).

Dois programas - Programa de Vigilância Alimentar e Nutricional e Programa de Complementação Alimentar - fizeram considerável uso de alimentos formulados sob as justificativas de que favorecem a operacionalização, têm boa aceitação, dificultam a diluição intrafamiliar e sua composição pode ser ajustada às neces- 


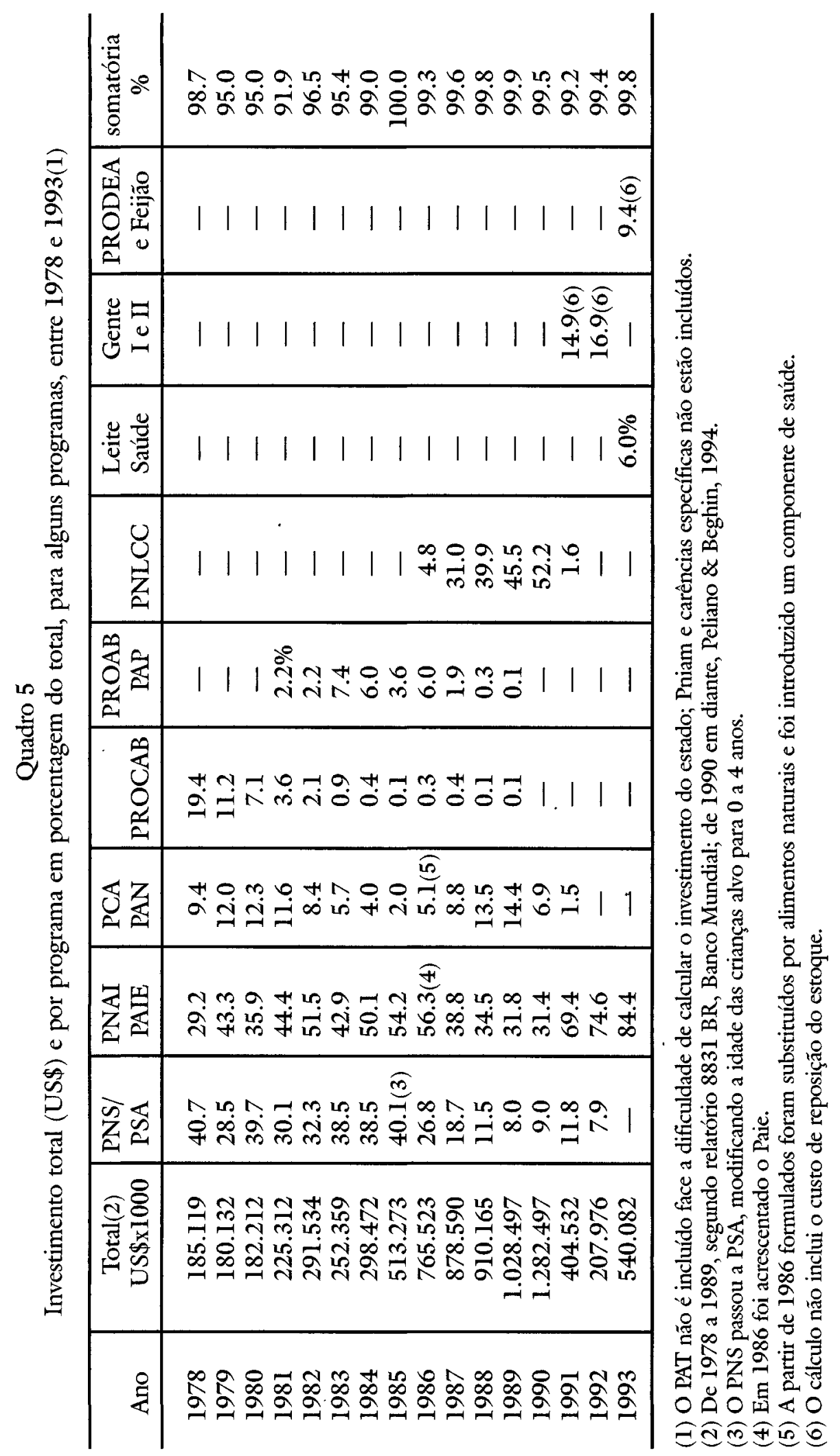


sidades da população-alvo. Todavia, em virtude dos custos mais elevados dos alimentos, o uso de formulados deve ter contribuído para encarecer esses programas, absorvendo parte dos escassos recursos destinados a programas sociais.

Os dados oficiais registram uma concentração das ações na região Nordeste, tanto em cobertura quanto em quantidade de alimentos (quadros 6 e 7). Todavia, os dados da Pesquisa Nacional de Saúde e Nutrição, em 1989, não apoiam essa interpretação:

- a cobertura real dos programas foi muito menor do que o anunciado oficialmente;

- os indicadores antropométricos melhoraram mais nos estratos de maior renda e nas regióes mais desenvolvidas do país, indicando que se mantiveram as diferenças regionais existentes;

- a distribuição de alimentos foi mais eficiente nas regiōes Sul e Sudeste que no Nordeste;

- o atendimento do Programa Nacional de Leite para Crianças Carentes se concentrou nas regiōes Sudeste e Sul, com forte predomínio das áreas urbanas;

- apenas cerca de $10 \%$ das gestantes foram atendidas pelos programas de suplementação alimentar;

- a cobertura do.Programa Nacional de Alimentação Escolar foi de 91\% na região Sudeste contra $\mathbf{5 7 \%}$ no Nordeste. O programa favoreceu os escolares de maior renda e, nas férias, a sua cobertura foi de apenas $7 \%$.

Quadro 6

Distribuição percentual dos alimentos por região e por programas (1975-1986)

\begin{tabular}{lrrrrr}
\hline Programa & N & NE & CO & SE & \multicolumn{1}{c}{ S } \\
\hline PNS & 6.2 & 77.5 & 7.7 & 8.5 & 6.0 \\
PSA & 6.7 & 56.8 & 5.7 & 20.5 & 10.5 \\
PROAB & $\overline{-}$ & 100.0 & - & - & - \\
PNAE & 7.6 & 44.9 & 9.7 & 18.8 & 19.0 \\
IRMÃOS & 10.6 & 51.3 & 4.6 & 13.6 & 19.9 \\
PAP(1) & 11.4 & 7.8 & 24.9 & 36.4 & 19.4 \\
PCA(2) & 5.4 & 59.9 & 24.9 & 4.3 & 6.1 \\
\hline
\end{tabular}

(1) As capitais do Nordeste são excluídas do PAP.

(2) Valores para 1985 e 1986, incluem leite, distribuído através dos Centros Atenção aos Desnutridos (CAD).

$\mathrm{Na}$ análise do Banco Mundial, em 1990, Pnae/PSA e PCA/PAN que, entre 1978 e 1989 absorveram, em média, 38,1\% dos recursos, tiveram pouca ou nenhuma influência na desnutrição infantil. 
Uma análise do Programa de Alimentos Básicos em Áreas de Baixa Renda (Proab) concluiu, em 1989, que esse programa se caracterizou como um mecanismo de transferência de renda sem impacto em nutrição infantil, por dois motivos: a prevalência de desnutrição em suas áreas de atuação era baixa e o aumento de poder aquisitivo gerado pelo programa foi direcionado para o consumo de bens não alimentícios.

O PAT, que, ao par de considerável volume de recursos envolveu a participação de 42.000 empresas e quase oito milhões de trabalhadores em 1992, inclui entre seus beneficiários trabalhadores em faixa de renda bem acima dos níveis de pobreza extrema, o que o classifica mais como política de transferência de renda do que como programa de combate à desnutrição. Acresce que, a exemplo do que ocorreu no Proab, não há demonstração de que os trabalhadores estejam transferindo a renda liberada para bens alimentícios em benefício dos grupos vulneráveis de suas famílias.

Apenas em dois programas houve avaliação bastante favorável: o Pcbe, que resultou em considerável redução do bócio endêmico; e o Pniam, em que uma análise, em 1988, mostrou resultados positivos, tais como:

- aumento do número de mães praticando aleitamento natural, misto ou exclusivo, em diferentes níveis de renda, inclusive entre as que trabalham fora do lar;

- maior aconselhamento e oferta de treinamento para aleitamento natural nos serviços de puericultura;

- maior apoio de pediatras e da enfermagem ao aleitamento natural;

- diminuição do assédio aos pediatras, por parte das empresas produtoras de substitutivos do leite materno.

Quadro 7

Distribuição percentual da população atendida por região (1975-1986)

\begin{tabular}{lcrrrr}
\hline Programa & N & NE & CO & SE & \multicolumn{1}{c}{ S } \\
\hline PNS & 6.2 & 67.9 & 7.5 & 11.2 & 7.1 \\
PSA & 7.8 & 48.6 & 8.1 & 24.6 & 12.4 \\
PROAB & - & 100.0 & - & - & - \\
PNAE $(1)$ & 9.7 & 41.8 & 9.0 & 22.5 & 16.9 \\
PCA & 4.3 & 65.5 & 4.8 & 21.9 & 3.5 \\
PNL & 1.0 & 32.8 & 12.7 & 48.9 & 4.7 \\
PAT & 3.7 & 10.9 & 3.0 & 70.5 & 11.9 \\
SAL $(2)$ & 0.8 & 46.1 & - & 35.0 & 18.1 \\
\hline
\end{tabular}

(1) Dados para 1985.

(2) Percentagem do sal que foi iodado e distribuido em cada regiāo. 
A melhora do estado nutricional da população entre o Estudo Nacional das Despesas Familiares (1974-1975) e a Pesquisa Nacional de Saúde e Nutriçáo (1989) tende a ser, ao menos em grande parte, atribuído a outros fatores que não aos programas de alimentação e nutrição, tais como:

- redução considerável do percentual da população abaixo da linha de pobreza absoluta;

- melhor distribuição de renda;

- considerável aumento da população urbana e melhoria nas condições de saneamento, principalmente a distribuição de água tratada, mas com grande predomínio da região Sudeste;

- considerável aumento na imunizaçáo contra sarampo, difteria, coqueluche e tétano;

- aumento discreto, mas significativo, na disponibilidade de leitos pediátricos;

- grande aumento nos partos hospitalares;

- diminuição do tamanho da família e maior espaçamento entre nascimentos;

- aumento na alfabetização e educação básica, com maiores índices para mulheres em idade reprodutiva.

Em conclusão, depois de mais de 20 anos de experiência, o Pronan, com um investimento equivalente a mais de US\$ 8 bilhóes e a distribuição de mais de sete milhões de toneladas de alimentos básicos e formulados, não chegou a afirmar-se como política nacional eficiente no combate à desnutrição. Para esse resultado negativo contribuíram vários fatores, entre os quais merecem destaque:

- falta de integração eficiente entre as ações em nutrição e em saúde;

- falta de vigilância, acompanhamento, avaliação e reorientação dos diversos programas, visando ao seu aperfeiçoamento;

- multiplicidade de programas, sem coordenação e articulação entre eles;

- atenção reduzida para com a área rural;

- irregularidades e incertezas na liberação de recursos.

Dois programas atualmente em andamento - Programa Nacional de Alimentação Escolar e Leite é Saúde - devidamente administrados, descentralizados, integrados com a rede de saúde e contando com a participação ativa da comunidade, poderão reunir condiçóes para atender aos grupos prioritários - gestantes, nutrizes, crianças e escolares - se a eles forem acrescentados os Programas de Incentivo ao Aleitamento Materno, Combate a Carências Específicas e um Sistema de Vigilância Alimentar e Nutricional. No caso das carências específicas, o uso de alimentos fortificados ou outras formas de administração de suplementos de vitaminas ou minerais deve ficar restrito às regióes de risco e acompanhado de avaliações epidemiológicas. As situações de emergência deverão ser enfrentadas com açóes oportunas nos modelos de Gente como a Gente, Distribuição de Feijāo 
ou Programa Emergencial de Distribuição de Alimento, de acordo com as disponibilidades.

Medidas dessa natureza, quando bem-administradas e mantidas com continuidade, deverão contribuir para melhorar consideravelmente as condiçóes de nutrição materna, infantil e pré-escolar, elevando os índices de alfabetização e a qualidade da educação fundamental. A mortalidade materna, infantil e pré-escolar, a prevalência da desnutrição atual e, a prazo um pouco mais longo, da desnutrição pregressa, deverão cair em níveis aceitáveis, mesmo nas áreas mais pobres.

Mas, embora esses resultados constituam meta altamente desejável, eles não representam uma solução socialmente justa e definitiva. Esta só será alcançada quando estiverem asseguradas condiçóes adequadas de educação, emprego, renda, habitação, saneamento e acesso a serviços de saúde, para toda a população.

\section{Notas}

\section{Lei 185, 1936.}

2 Atualmente ligado à Universidade Federal do Rio de Janeiro.

3 Lei 5.929, 30 de novembro de 1972.

4 Decreto 73.996 de 30 de abril de 1973.

5 O Pronan III, planejado para o período 1982-1985, prevendo medidas inovadoras como a criação de um Fundo Nacional de Alimentação e Nutrição e a transformaçăo do Inan em empresa pública, não chegou a ser implantado: o Pronan II foi mantido até 1990, quando foi praticamente extinto.

6 Loan 1302 BR, no total de US\$ 72 milhóes, US\$ 53 milhōes do Governo brasileiro e US\$ 19 milhóes do Banco.

7 Ministério da Agricultura.

8 Renda familiar de até dois salários mínimos.

9 Reduzido para 36 meses em 1989.

10 O PSA começou a decrescer a partir de 1987 e, em 1993, deu lugar ao programa Leite é Saride.

11 O Proab baseou-se na observação de que os preços dos alimentos praticados por pequenos varejistas que abastecem a população pobre são mais altos do que os dos supermercados. Os alimentos eram arroz, açúcar, charque, farinha de mandioca, feijão, fubá, leite em pó, óleo, macarrão, peixe salgado e ovos. $\mathrm{O}$ abastecimento dos pequenos varejistas era feito pela Cobal, com subsídio do Inan.

12 Além do Procab foi também desenvolvido o Pater, com o objetivo de estimular a produçâo de alimentos pelos pequenos agricultores, através da extensão rural e crédito. Em 1979 o progra- 
ma atingiu 40.784 produtores em 141 municípios do Nordeste. Outro projeto que não chegou a ter impacto foi o Modelos Agroindustriais para Pequenos Produtores e Pescadores.

13 Programa de Açôes Integradas da Saúde da Mulher e da Criança, Ministério da Saúde.

14 Com o aumento na produção de cápsulas de sulfato ferroso plancjava-se incluir o programa como parte do PSA a partir de 1978.

15 Antropometria, hemoglobinemia, retinol sérico, bócio, vários aspectos do desmame, consumo e produçáo de alimentos, salário e renda, preços e natalidade.

16 Conforme referido no início, o Pnae, sob o título de Merenda Escolar, foi instalado em 1955, 18 anos antes da criação do Pronan.

17 A inclusão de pré-escolares (quatro a seis anos) no Pnae é bem anterior ao Paie. Este, apenas estruturou esse componente como programa em separado.

18 Posteriormente designado como Programa de Atenção aos Desnutridos - PAN, ou PAN/PCA, ou também PAN/CAD porque distribuía leite através dos Centros de Atenção aos Desnutridos - CADs.

19 Os formulados desenvolvidos pela Faculdade de Tecnologia de Alimentos da Unicamp cram mamadeiras para crianças até um ano, milkshake, um a três anos, esopa, para gestantes e nutrizes. Posteriormente estes formulados foram substituídos por dois de mais baixo custo: sopa (fubá, feijão e soja) para gestantes e mingan (leite em pó e fubá), para crianças de seis a 36 meses.

20 Feijão, arroz, farinha, fubá, leite em pó, óleo.

21 De acordo com a Lei 6.321 e Decreto 78.678 cabia à empresa $32 \%$ e ao estado $42 \%$, todavia, em virtude das restriçóes para deduções do IR, a contribuição média da empresa foi de $20 \%$.

22 Arroz, feijão, açúcar, café, farinha de mandioca, óleo de soja, macarão, ovos, fubá, farinha de trigo, sal farinha de milho.

23 Transformada cm Companhia Nacional de Abastecimento - Conab.

24 Pesquisa Nacional de Saúde e Nutrição - PSN 1989 (Inan, Ibge, Ipea).

25 Em 1992 foram também distribuídas 1.349 toneladas de leite em pó oriundo do extinto Pnlcc.

26 No GG I foram usados 407.655 toneladas de alimentos em estoque, no valor de US $\$ 60,4$ milhôes. No GG $\Pi$ foram liberados dos estoques apenas 150.000 toneladas de arroz e o restante veio dos programas da LBA. O custo de reposição dos alimentos liberados do estoque era bem superior aos custos referidos.

27 Em 1993, o programa recebeu US\$ 32 milhöes, assinando convênios com 286 prefeituras em atendimento de 723.000 beneficiários ( 203.000 crianças desnutridas, 323.000 irmãos e 127.000 gestantes), até fevereiro de 1994. Predominam o Nordeste com $72 \%$ dos beneficiados. $\mathrm{O}$ custo mensal médio por beneficiário é em torno de US\$ 9,00.

28 No final de $1993,48,3 \%$ dos beneficiários já eram atendidos através das prefeituras.

29 Em 1993, o orçamento do Pnae era de US\$ 770 milhōes, mas, em virtude do atraso e da inflação, a quantia liberada foi equivalente a US\$ 456 milhões. 
30 O PAT representa uma complementação de renda de mais de $50 \%$ para trabalhadores com um salário mínimo.

31 O programa surgiu da necessidade de esvaziar parte dos armazéns para armazenagem da nova safra.

32 Arroz, milho, feijão e farinha de mandioca.

33 Grupo de Trabalho Interministerial para Coordenação das Açóes na Área de Alimentação e Nutrição - Gtca, 1985; Grupo Executivo Interministerial para Assuntos de Alimentação Popular - Geiap, 1986; Conselho Consultivo Técnico-Científico do Inan, 1987.

\section{Referências bibliográficas}

ASSESSING Nutricional Problems in Brazil World Bank, Sector Report 8881BR, 1990.

CARVALHO DA SILVA, A. Politicas de alimentação e nutriģão no Brasil. São Paulo, jan. de 1979 (mimeo).

. A situagẫo nutricional do Brasil. São Paulo, jul. de 1987 (mimeo).

. Estudio sobre investigaciones alimentario-nutricionales para poblaciones de bajos ingressos en Latinoamerica y el Caribe. Washington, Organización Panamericana de la Salud, Caderno Técnico n. 21, 1990.

MONTEIRO, C. A.; BENICIO, M.H. D'A. \& GOUVEIA, N. E. Sauide e nutriçño das crianf̧as brasileiras no final da década de 80 (mimeo).

MUSGROVE, P. Que los pobres comam mejor. Evalución de programas destinados a mejorar el consumo alimenticio de familias pobres en Brasil. Mar. de 1986 (mimeo).

PELIANO, A. M. M. Os Programas de nutrif̧ão para máes e crianfas no Brasil. Perfil estatístico de crianças e mães no Brasil. Aspectos de sauide e nutriçâo de crianças no Brasil. Rio de Janeiro, Ibge, 1989.

PELIANO, A. M. M. \& BEGHIN, N. O papel do Estado na área de alimentaf̧ão e nutriģão. Brasília, Ipea, 1992.

. Programas de alimentaģão para criangas e adolescentes. Qual o destino? Ipea, Relatório interno, out. de 1992.

. Os programas federais de alimentação e nutriģ̃ão no inicio da década de 90 . Brasillia, abr. de 1994 (mimeo).

REA, M. F. As políticas de alimentação infantil e a prática de amamentar. $O$ caso de São Paulo (Tese de Doutorado). Fac. de Saúde Pública, USP, 1989.

Alberto Carvalho da Silva é professor honorário do Instituto de Estudos Avançados da USP.

Texto apresentado no seminário Pobreza, fome e desnutriçẩo no Brasil realizado em 2 de dezembro de 1994 no IEA-USP. 